\title{
UNEXPLAINED HEART FAILURE IN THE AGED
}

BY

\author{
G. A. ROSE AND R. R. WILSON \\ From Paddington General Hospital, Paddington \\ Received November 19, 1958
}

Failure of the heart is frequent in old people. The clinician often assumes that myocardial ischæmia is invariably a factor in its ætiology (Bedford and Caird, 1956); but sometimes the pathologist can neither confirm this diagnosis nor suggest any other adequate explanation. Faced with this common clinical problem we decided to collect data about such cases, in the hope of clarifying their ætiology.

\section{MATERIAL AND Methods}

The study has been based retrospectively on 50 consecutive necropsies on patients who died, at an age of 70 years or more, with heart failure for which the clinician could find no adequate explanation. Thus, cases were excluded from the series if they showed evidence of valvular disease (other than "functional" mitral or tricuspid regurgitation), anæmia (hæmoglobin of $10 \mathrm{~g}$. per $100 \mathrm{ml}$, , or less), emphysema, malnutrition or vitamin deficiency, thyrotoxicosis, or ischæmic heart disease (history of angina pectoris or cardiac infarction, or electrocardiographic evidence of infarction). Cases in which heart failure was merely a terminal complication of some other condition, such as pneumonia or surgical operation were also excluded.

Cases were accepted in which there was evidence of either left ventricular failure (dyspnœa, orthopnœa, and bilateral basal fine râles not attributable to pneumonia) or right ventricular failure (œdema and jugular venous congestion). In fact, most patients showed both and there was isolated left ventricular failure in two only and isolated right ventricular failure in six only.

It became obvious that a proper assessment of the importance of various common conditions -hypertension, coronary disease, and brown atrophy, for example-would require some standard by which to estimate their general incidence in the elderly. Each heart failure subject was therefore matched by the next person of the same sex and age ( \pm 3 years) who came to necropsy without evidence of heart failure, and also without any of the clinical conditions specified earlier as possible causes of heart failure. Patients were excluded from the control group if their hospital admission or death was due to any disease likely to be related to atheroma, hypertension, or cor pulmonale.

In any retrospective controlled investigation it is essential to know whether observations were made with equal thoroughness in the two groups. In the present study this may not have been achieved with regard to some of the clinical data; such instances will be discussed as they arise. With regard to the necropsy reports it can fairly be claimed that, whether or not there was any heart failure, a standard routine was followed in all cases. The procedure for examining the heart consisted of incising all chambers, then inspection of the valves, followed by opening up the chambers, measuring the valves, making several transverse cuts across the main coronary arteries and their larger branches, and incising the walls of the ventricles. The observations that will be presented have been restricted to those regularly included in this standard routine. One of us conducted all but 11 of the necropsies; the remainder (6 on cases of heart failure, and 5 on controls) were undertaken by Dr. J. Guthrie. 


\section{RESULTS}

The 50 subjects comprised 18 men and 32 women. Analysis of their age distribution (Table I) shows that the excess of women occurred among those aged 80 years or more.

TABLE I

Age of Subjects and Causes of Death

\begin{tabular}{|c|c|c|c|c|c|c|}
\hline \multirow{2}{*}{\multicolumn{2}{|c|}{ Age (years) }} & \multicolumn{2}{|c|}{ Number of subjects } & \multirow{2}{*}{ Cause of death } & \multicolumn{2}{|c|}{ Number of cases } \\
\hline & & Men & Women & & Heart failure group & Control group \\
\hline $\begin{array}{l}70-74 \quad \ldots \\
75-79 \quad \ldots \\
80-84 \quad \ldots \\
85-89 \quad \ldots \\
90 \text { and over } \\
\text { Mean age }\end{array}$ & $\begin{array}{l}\cdots \\
\cdots \\
\cdots \\
\cdots \\
\cdots\end{array}$ & $\begin{array}{r}4 \\
11 \\
3 \\
0 \\
0 \\
77 \text { years }\end{array}$ & $\begin{array}{r}7 \\
10 \\
9 \\
4 \\
2 \\
83 \text { years }\end{array}$ & 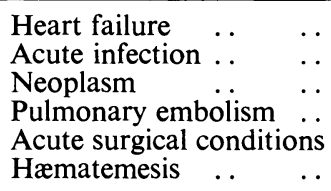 & $\begin{array}{r}33 \\
7 \\
5 \\
3 \\
2 \\
0\end{array}$ & $\begin{array}{r}-17 \\
16 \\
6 \\
7 \\
4\end{array}$ \\
\hline
\end{tabular}

Estimation of the duration of heart failure was often made difficult by the patients' mental state. Among the 37 who could give a reasonably clear history, $16(43 \%)$ had had heart failure for a year or more before hospital admission, and $9(24 \%)$ for less than three months. No clear correlation could be discerned between the duration of failure and any of the other features to be described, apart from a tendency towards a longer duration in those with heavier hearts. Survival after hospital admission was mostly brief, three-quarters of the cases (both men and women) dying within one month.

The causes of death are set out in Table I; there were no important differences between the sexes. In many of the deaths attributed to heart failure, bronchopneumonia was a contributory cause.

Table II describes the incidence of various types of cardiac rhythm. Ectopic beats occurred with equal frequency in the two groups; and auricular fibrillation also was not uncommon among the controls.

TABLE II

TYPES OF CARDIAC RHYTHM

\begin{tabular}{|c|c|c|c|c|c|}
\hline \multirow{3}{*}{ Type of rhythm } & & \multicolumn{4}{|c|}{ Number of subjects } \\
\hline & & \multicolumn{2}{|c|}{ Men } & \multicolumn{2}{|c|}{ Women } \\
\hline & & Heart failure & Control & Heart failure & Control \\
\hline $\begin{array}{l}\text { Sinus rhythm } \\
\text { With ectopic beats } \\
\text { Auricular fibrillation } \\
\text { Idioventricular .. }\end{array}$ & $\begin{array}{l}\ldots \\
\ldots \\
\ldots \\
\ldots\end{array}$ & $\begin{array}{l}9 \\
2 \\
6 \\
1\end{array}$ & $\begin{array}{r}15 \\
2 \\
1 \\
0\end{array}$ & $\begin{array}{r}12 \\
5 \\
14 \\
1\end{array}$ & $\begin{array}{r}23 \\
4 \\
5 \\
0\end{array}$ \\
\hline
\end{tabular}

Auricular fibrillation occurring in old people in the absence of valvular disease or thyrotoxicosis is usually ascribed to myocardial ischæmia, whether or not there is independent evidence for this. The incidence at necropsy of major coronary disease (i.e. significant stenosis or an occlusion or myocardial infarction or fibrosis) in cases with and without auricular fibrillation is shown below: data for heart failure and control subjects have been combined. Major coronary disease was found in 31 per cent of those with auricular fibrillation, and in 30 per cent of those without fibrillation.

Major coronary disease present Major coronary disease absent

$\begin{array}{cccc} & & \text { Fibrillation present } & \text { Fibrillation absent } \\ \ldots & \ldots & 8 & 22 \\ \cdots & \cdots & 18 & 52 \\ & & \frac{18}{26} & 74\end{array}$


Equally there was no evidence of an association between auricular fibrillation and cardiac hypertrophy or atrophy at necropsy. It appeared nevertheless that fibrillation tended to be associated with dilatation of the heart: all but 1 of the 13 patients in this group in whom the chest was $\mathrm{X}$-rayed showed an increase in the transverse diameter of the heart, as compared with only 25 out of 40 of those without fibrillation.

Of the two patients with complete heart block, one had severe coronary disease and a fibrotic myocardium. In the other, however, the heart appeared completely normal at necropsy, and sections of the atrio-ventricular bundle showed no evidence of disease.

The reliability of data on blood pressure distribution (Table III) is open to criticism. The figures

TABLE III

Blood Pressure Distribution

\begin{tabular}{|c|c|c|c|c|c|}
\hline \multirow{3}{*}{$\begin{array}{l}\text { Blood pressure } \\
\text { (mm. mercury) }\end{array}$} & & \multicolumn{4}{|c|}{ Number of subjects } \\
\hline & & \multicolumn{2}{|c|}{ Men } & \multicolumn{2}{|c|}{ Women } \\
\hline & & Heart failure & Control & Heart failure & Control \\
\hline 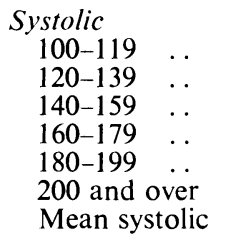 & $\begin{array}{l}\ldots \\
\cdots \\
\cdots \\
\ldots \\
\cdots \\
\ldots\end{array}$ & $\begin{array}{r}3 \\
2 \\
8 \\
2 \\
1 \\
0 \\
142 \mathrm{~mm} .\end{array}$ & $\begin{array}{r}4 \\
1 \\
8 \\
2 \\
0 \\
1 \\
141 \mathrm{~mm} .\end{array}$ & $\begin{array}{r}5 \\
5 \\
9 \\
7 \\
2 \\
2 \\
147 \mathrm{~mm} .\end{array}$ & $\begin{array}{r}1 \\
6 \\
10 \\
4 \\
6 \\
1 \\
150 \mathrm{~mm} .\end{array}$ \\
\hline $\begin{array}{c}\text { Diastolic } \\
60-79 \\
80-99 \quad \ldots \\
100-105 \quad \ldots \\
\text { Mean diastolic }\end{array}$ & $\begin{array}{l}\ldots \\
\cdots \\
\ldots \\
\ldots\end{array}$ & $\begin{array}{r}5 \\
10 \\
1 \\
82 \mathrm{~mm} .\end{array}$ & $\begin{array}{c}5 \\
8 \\
3 \\
83 \mathrm{~mm} .\end{array}$ & $\begin{array}{c}10 \\
14 \\
6 \\
86 \mathrm{~mm} .\end{array}$ & $\begin{array}{r}9 \\
14 \\
5 \\
82 \mathrm{~mm} .\end{array}$ \\
\hline
\end{tabular}

taken were those recorded by the houseman at the time of the patient's admission to hospital, except where these were obviously out of line with values recorded earlier or later. In 10 patients (4 with heart failure and 6 controls) it was obvious that the patient was shocked or severely ill when the blood pressure was measured: data from these have been excluded. Comparison of the distribution in the various groups indicates little difference between those with and those without heart failure, apart perhaps from a slight downwards shift of systolic levels in the women with heart failure. Calculation of the standard errors confirms that the various means do not differ significantly. There was no evidence in any group of a tendency for blood pressure to increase with age, which agrees with the findings of Master et al. (1957), who studied arterial pressures in healthy old people.

Whereas the clinical observations did not suggest that many of these patients had had hypertension, a different conclusion is suggested by examination of their heart weights at necropsy (Table IV). Men with heart failure clearly tended to have heavier hearts than their controls (difference between means $=2.99 \times$ S.E., $\mathrm{P}<0.01$ ) ; the difference was less in the case of women $(1.50 \times$ S.E., $\mathrm{P}<0 \cdot 1,>0 \cdot 05)$. The blood pressure as measured at the time of admission to hospital gave little or no indication of the weight of the heart. In two patients with very heavy hearts ( $>500$ g.) the blood pressures were known a year before the onset of failure, and were respectively only $180 / 80$ and $150 / 95 \mathrm{~mm}$. A number of control patients also had heavy hearts, despite normal blood pressures at the time of their admission.

There was some evidence of an association between heart weight and the duration of failure prior to admission. The mean duration for those with heavy hearts $(400 \mathrm{~g}$. or more for men, 
TABLE IV

Heart Weights at Necropsy

The numbers with a diastolic pressure of $100 \mathrm{~mm}$. $\mathrm{Hg}$ or more are given in brackets

\begin{tabular}{|c|c|c|c|c|}
\hline \multirow{3}{*}{$\begin{array}{l}\text { Heart weight } \\
\text { (g.) }\end{array}$} & \multicolumn{4}{|c|}{ Number of subjects } \\
\hline & \multicolumn{2}{|c|}{ Men } & \multicolumn{2}{|c|}{ Women } \\
\hline & Heart failure & Control & Heart failure & Control \\
\hline $\begin{array}{ll}150-199 & \\
200-249 & . \\
250-299 & . \\
300-349 & . \\
350-399 & . \\
400-449 & . \\
450-499 & . \\
500 \text { and over } \\
\text { Mean weight }\end{array}$ & $\begin{array}{c}1 \\
0 \\
2 \\
2 \\
2(1) \\
1 \\
3 \\
7 \\
436 \mathrm{~g} .\end{array}$ & $\begin{array}{c}0 \\
6(3) \\
4 \\
3 \\
1 \\
0 \\
2 \\
2 \\
320 \mathrm{~g} .\end{array}$ & $\begin{array}{l}0 \\
8(2) \\
7(2) \\
6 \\
4(1) \\
4 \\
3(1) \\
0 \\
324 \mathrm{~g} .\end{array}$ & $\begin{array}{l}3 \\
9(3) \\
7(1) \\
6 \\
3 \\
2(1) \\
1 \\
1 \\
295 \mathrm{~g} .\end{array}$ \\
\hline
\end{tabular}

$350 \mathrm{~g}$. or more for women) was 7.5 months, as compared with 4.7 months for those with smaller hearts: the standard error of the difference is 3.4 months, $\mathrm{P}<0 \cdot 2,>0 \cdot 1$. There was no correlation between heart weight and the order in which the ventricles appeared to have failed, nor between heart weight and the severity of coronary disease. Hypertrophy of the heart usually involved both ventricles, but especially the left. In only two instances was there isolated hypertrophy of the right ventricle. Both of these showed emphysema, and one (a control) also showed hyalinization of the walls of the smaller pulmonary arteries.

The frequency of heart failure in patients with small hearts is also noteworthy; this was especially common among the women. It is contrary to the experience of Sonnek (1954), who says that "the small atrophic heart commonly found in old people does not go into congestive heart failure; it is the larger heart which fails".

Data on the severity of coronary artery disease are presented in Table V. The incidence of

TABLE V

Incidence of Coronary Artery Disease at Necropsy

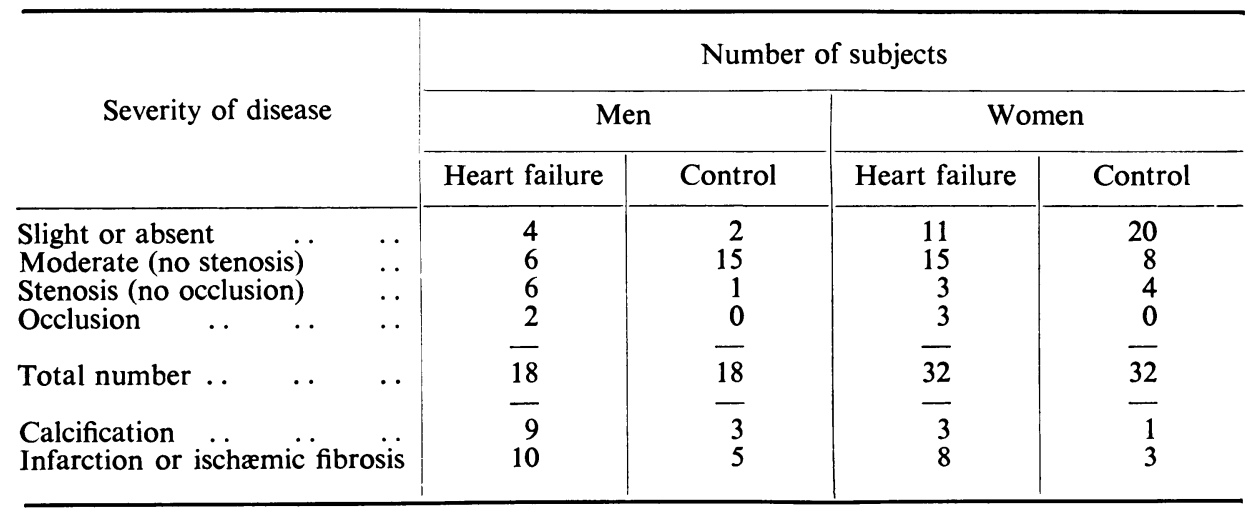

infarction or ischæmic fibrosis was higher in the heart failure group $(36 \%)$, although not small $(16 \%)$ among the controls. The figures for coronary calcification were 24 and 8 per cent respectively, and for coronary stenosis or occlusion they were 28 and 10 per cent. The excess incidence of coronary stenosis or occlusion in the heart failure group occurred chiefly in the men. The total 
incidence of major coronary artery disease (coronary stenosis or occlusion, or myocardial infarction or fibrosis) was 38 per cent in the heart failure group, and 22 per cent in the controls.

Brown atrophy of the myocardium is sometimes regarded as a possible cause of heart failure. Its incidence in the present series was 20 per cent among heart failure subjects and 36 per cent in the controls. The incidence of fatty change and of cloudy swelling was almost identical in the two groups.

There remains a large group of patients in whom necropsy revealed no explanation for heart failure. After excluding (a) patients with a diastolic blood pressure of $100 \mathrm{~mm}$. or more, (b) those with heavy hearts (400 g. or more for men, $350 \mathrm{~g}$. or more for women), and (c) those with major coronary disease (as defined earlier), there remain still 3 men and 15 women. The average weight of their hearts was $248 \mathrm{~g}$.; they had no valvular disease, nor did they show evidence of right ventricular hypertrophy, significant pulmonary disease, or disease of the thyroid gland. Their average age was 79 years ( 2 years below that for the whole series).

Electrocardiographic records were available in only 12 of the 50 subjects. Apart from the confirmation of the nature of arrhythmias, the abnormalities comprised left ventricular strain (9 patients), general flattening of $T$ waves (1 patient), and bundle-branch block ( 3 patients).

\section{Discussion}

This study represents an attempt to assess the frequency of certain clinical and pathological features in old people with heart failure of obscure cause. All were fatal hospital cases, and conclusions as to the frequency of the various conditions observed cannot therefore be transferred to the wider population of the aged whose hearts are failing; for, as Bedford and Caird (1956) have shown, many such cases follow a comparatively benign course.

Within the study, comparisons have been drawn between the subjects with heart failure and control subjects who were matched for age and sex. The latter are not, however, a random cross-section of the population, but were selected by virtue of their having suffered from some fatal disease. The latter must certainly have influenced the state of their cardiovascular system, particularly as regards blood pressure, and perhaps also, for example, as to brown atrophy and fatty change in the myocardium. It seems unlikely, however, to have influenced significantly the two criteria to which most importance has been attached: namely, heart weight and coronary artery disease. Care was taken to exclude from the control group those subjects whose arrival at necropsy was likely in any way to be connected with a condition that might influence these two major criteria. For instance, subjects were excluded who died of bronchopneumonia secondary to a stroke or to chronic pyelonephritis.

Criticism may be voiced at the retrospective use of data that were not collected as part of a planned investigation. This would certainly be justified with regard to such clinical features as the presence of gallop rhythm or systolic murmurs: consequently such observations have not been mentioned. Of the data that are presented, some (such as pulse rhythm and heart weight) are reliable objective observations. As to the assessment of coronary disease, it must be admitted that post-mortem examination of the heart, in the manner described, sometimes leaves one unsatisfied. Calcification of the coronary arteries may prevent the observation of stenosis and thrombosis. It is hard to assess the significance of degenerative fibre changes seen with the microscope, particularly because it is difficult to define the proportion of the myocardium that is involved. Least of all, perhaps, can one make any useful judgement of the state of the nodes and conducting tissues. All these matters really require the expenditure of much labour in a specialized laboratory, not to mention the acquisition of new knowledge. Meanwhile we cannot deny that we are often unable to interpret post-mortem appearances in terms of myocardial function. Nevertheless, it is claimed that the necropsy routine followed at this hospital justifies our fairly simple classification of the anatomical changes in the coronary arteries; and such bias as may have been introduced by observer error would lead to the under-estimation of disease in the control group rather than in the heart failure cases, since the hearts of the latter would be scrutinized more carefully. 
In a group, such as the present, of cases of clinically obscure heart failure, it seems that there are three main factors that might be common causes for the failure: firstly, preceding hypertension, now abated by the onset of heart failure; secondly, myocardial ischæmia that has eluded the physician's search; or thirdly, and as yet uncertainly, some degenerative process associated with ageing itself.

It is generally considered that the onset of heart failure may lead to a lowering of a previously high blood pressure (e.g. White, 1951), thus obscuring the true diagnosis in a case seen for the first time at this stage. Wood (1956), however, denies this possibility. The data on heart weight presented here strongly suggest that almost a half of the patients had had previous hypertension. It does not, of course, follow that hypertension was the sole cause of failure in all such patients; indeed, a striking feature was the frequency of cardiac hypertrophy in the control group, 16 per cent of whom had hearts weighing $400 \mathrm{~g}$. or more. It was clear in both groups that measurement of the blood pressure in an ill old person gives practically no indication of heart weight, and hence, by inference, of the usual level of the arterial pressure.

The possibility of clinically undetectable myocardial ischæmia has provided the physician with an easy diagnosis for all cases of obscure heart failure or auricular fibrillation in old people. Thus Bedford and Caird (1956) state, as though it were self-evident, that "myocardial ischæmia ... is presumed to be a constant ætiological factor in this age-group". Those of their patients in whom there was no ascertainable cause for heart failure are referred to as the "normotensive ischæmic group". In our series the incidence of major coronary disease was 38 per cent in the heart failure group and 22 per cent in the control group. One cannot conclude that coronary disease was the cause of failure wherever the two occurred together; but the greater incidence of major disease in the heart failure group suggests that it was important in at least a proportion of them.

The existence of auricular fibrillation did not seem to bear any relation to the presence of major coronary disease; indeed, many of the subjects with fibrillation had hearts that at necropsy appeared healthy in all respects. Nevertheless, fibrillation was more frequent in the heart failure group, and was almost constantly associated with radiological evidence of cardiac enlargement.

Perhaps the most interesting observation to emerge from this study is the frequency with which necropsy on old people with heart failure and normal blood pressure fails to show any anatomical abnormality in the heart. In 36 per cent of all patients the coronary arteries showed no major disease, the heart weight was normal, and there was no evidence of pulmonary heart disease. Brown atrophy, fatty change, and (in life) auricular fibrillation were not more common in these patients than in the series as a whole. Previous reports on heart failure in the aged have not emphasized the frequency of this type of case. It is not mentioned at all by Gavey (1949), Stroud and Wagner (1949), Bedford and Caird (1956), Herrmann and Hejtmancik (1957), Paul (1957), or Priest (1957). Lewis (1946) wrote of "the heart that fails in old age without displaying any of the major antecedent troubles", and commented that "the bodily reserves have usually begun to decline long since and among them is the cardiac reserve". It seems, however, that he had in mind cases of sudden collapse rather than of chronic congestive failure, for he continued by saying that these patients "pass out unobtrusively, after brief illness, or without warning, while sitting in their chairs or sleeping in their beds". Sonnek (1954) merely states in passing that "I have also seen gross heart failure with little anatomic change".

In our series chronic failure of a structurally normal heart was common, and it does not seem unreasonable to postulate that we may here be dealing with a myocardium that has been weakened through some process connected with age itself. The pathologist, by examination of the heart alone, cannot tell if a patient has died with heart failure. Campbell (personal communication) has taught for years that he cannot distinguish between two large hearts, both from patients with hypertension, one of whom has died after a road accident and the other after congestive failure. We are already familiar in the aged with the paradox of failure of the mind and weakening of the limbs that are not reflected post mortem in any visible change in the brain or muscles; and these changes afflict individuals of the same age in widely differing degrees. It is possible that a similar obscure 
weakening may also affect the myocardium. Nevertheless, such a hypothesis must not be too readily adopted, lest it should obscure some cause of myocardial failure more specific than mere senility.

It thus appears that, on the basis of the necropsy findings, our cases can probably be divided into three ætiological groups: first, those with former hypertension; secondly, those with occult myocardial ischæmia; and thirdly, those with normal blood pressures and with hearts of normal appearance. This last entity can perhaps be referred to as "senile heart failure", provided one recognizes that the term "senile" is purely descriptive and does not of necessity imply the absence of any more specific underlying cause. It is clear that much remains to be learnt.

From the clinician's point of view it is disappointing that our analysis has indicated no means of distinguishing in life between these very different types of case. This difficulty does, however, serve as a warning against the diagnosis of myocardial ischæmia in all cases of clinically obscure heart failure in the aged.

\section{SUMMARY}

An analysis is presented of the clinical and post-mortem findings in 50 patients who died at an age of 70 years or more with heart failure for which the clinician could find no adequate explanation. They have been compared with a group of 50 patients, matched for age and sex, in whom prior to death there was no reason to suspect heart disease.

The heart failure can probably be divided ætiologically into three groups-former hypertension, clinically unrecognized coronary disease, and cases in which the heart at necropsy appeared completely normal. The last may possibly be examples of "senile heart failure". Auricular fibrillation, which was common in all ætiological groups and also among the control subjects, did not appear to be related to coronary disease.

We are indebted to the consultant staff of Paddington General Hospital for permission to make use of clinical data from their patients.

\section{REFERENCES}

Bedford, P. D., and Caird, F. I. (1956). Quart.J. Med., N.S. 25, 407.

Gavey, C. J. (1949). Lancet, $2,725$.

Herrmann, G. R., and Hejtmancik, M. P. (1957). Geriatrics, 12, 621.

Lewis, T. (1946). Diseases of the Heart. 4th ed., p. 249. Macmillan \& Co., London.

Master, A. M., Lasser, R. P., and Jaffer, H. L. (1957). Proc. Soc. exp. Biol. Med., 94, 463.

Paul, O. (1957). J. Amer. Geriatrics Soc., 5, 757.

Priest, W. S. (1957). Geriatrics, 12, 290.

Sonnek, P. J. (1954). Geriatrics, 9, 75.

Stroud, W. D., and Wagner, J. A. (1949) in Geriatric Medicine (ed. E. J. Stieglitz), p. 385. W. B. Saunders Co., Philadelphia \& London.

White, P. D. (1951). Heart Disease. 4th ed., p. 472. The Macmillan Co., New York.

Wood, P. (1956). Diseases of the Heart and Circulation. 2nd ed., p. 771 . Eyre \& Spottiswoode, London. 